\title{
Etik İle Estetik Arasında Türk Edebiyatçısı Yahut Bir Mürşit Olarak Romancı
}

Ertan ENGIN*

$\ddot{O} \mathbf{z}$

Yeni Türk edebiyatının başlangııından itibaren; Rasyonalist Şinasi'den, Romantik Namık Kemal'e ondan Natüralist Nâbizâde Nâzım'a ve orta sınıfın sesi olan Ahmet Mithat'a kadar, sanat ve edebiyatın etik, ahlakî bir vurgusu olması gerektiğine inanan ve bunu dile getiren çok sayıda edebiyatçı saymak mümkündür. Söz konusu etik, ahlakî vurgu Servet-i Fünûn'a gelindiğinde hem daha c1lızlaşır hem de daha da önemli olarak -en azından bize göre- farklı bir boyuta taşınıp, etik estetiğin içinde eritilir. Dolayısıyla Birinci ve İkinci dönem Tanzimat edebiyatçıları ile Servet-i Fünûn topluluğu arasındaki ayrışmayı/mesafeyi aynı zamanda bu noktadan da temellendirmek olasıdır. Kabaca ve genel olarak belirtmek gerekirse bu iki tavır, günümüze dek izlerini belirgin yahut örtük biçimde bırakarak devam eder. Edebiyat/estetik ile etik arasında akrabalığı bir postüla olarak kabul edenler ve salt estetiğin dahi etiğe hizmet ettiğine inananlar. Bu yazı daha ziyade birinci grubun zihin yapısına ilişkin kimi irdelemeleri içermekte, bu yapının mesele ettiği ve etmediği bazı problematikleri ortaya koymayı ve bunlar üzerinde düşünmeyi amaçlamaktadır.

Anahtar Kelimeler: Edebiyat, etik, estetik, kurmaca, mesaj

\footnotetext{
* Doç. Dr., Necmettin Erbakan Üniversitesi, Sosyal ve Beşeri Bilimler Fakültesi, Türk Dili ve Edebiyatı Bölümü. Elmek: uengin@gmail.com
} 


\title{
Turkish Man of Letters Between Ethics and Aesthetics or Novelist as a Mentor
}

\begin{abstract}
It is possible to mention numerous men of letters believing and uttering that art and literature should have an ethical and moral accent as from the beginning of New Turkish Literature; from Şinasi the rationalist to Namık Kemal the romantic, from Nabizade Nazim the naturalist to Ahmet Mithat who was the voice of the middle class. Aforesaid this ethical and moral accent both loses strength and is melted within ethics and aesthetics gaining a different dimension in Servet-i Fünun -at least according to us. Thereby, it is probable to found the divergence betwixt the first and the second term Tanzimat literature, and Servet-i Fünun community. Roughly and generally, these two attitudes continue leaving a trace distinctly or implicitly by now. The ones who admit the relationship between literature/aesthetics and ethics as a postulate or the ones believing that even only aesthetics serves ethics. This article is more concerned about some probes regarding the frame of mind of the first group. It aims to set forth some problematics which this frame make an issue of and not, and aims to think on them.
\end{abstract}

Keywords: Literature, Ethics, Aesthetics, Fiction, Message 
Yeni Türk edebiyatının erken dönem yazarları-Natüralist Nâbizâde Nâzım dahi-, tasfiye-i vicdan, tehzîb-i ahlak gibi ifadeleri edebiyattan bahseden yazılarında kullanırken, zihinlerindeki sanat/edebiyat/estetik ile etik arasındaki epistemolojik bir bağ olduğuna dair inançlarını da dışa vurmuş oluyorlardı. Özellikle Tanzimat dönemi yazarları için estetiği etiksiz düşünmek mümkün değildi. Servet-i Fünûn'a duyulan tepkinin ardında biraz da bu yatıyordu. Servet-i Fünûn yazarı için -Halit Ziya, Mehmet Rauf hemen akla ilk gelenlerdendirestetiğin kendisi bizatihi etiktir. Tanzimat yazarı; ibret, hikmet gibi kavramlarla birlikte düşünür yazmayı. ${ }^{1}$ Servet-i Fünûn yazarı için başat değer ibret ve hikmet değildir. Onun için en büyük hikmet ve ibret, kalpteki duyguların tahlili, 'toplumsal'ın teşrihidir. ${ }^{2}$ Tanzimat döneminin basın ve edebiyat alanında en önde gelen isimlerinden Ahmet Mithat, biraz da bu ibret konusuyla ilgili olarak kendi etiğini Kur'ân'daki Tîn Sûresi'nden yola çıkarak temellendirir (Ahmet Mithat 2001: 239, 243). ${ }^{3}$ Mîzancı Murat'ın edebî eleştirilerinde de etik, ahlak değerleri belirleyici rol oynar (M. Murat 1994: 379-440). ${ }^{4}$

Fikret'in nesirlerindeki şu paragraf ise Servet-i Fünûn grubunun sanat/ edebiyat/estetik ile bunlara ilişkin etik, ahlâkî beklentiye dair diyalektik çözümü sunan iyi bir pasajdır: "Birçokları derler ki edebiyat tasfiye-i ahlâka, tenvîr-i vicdana hizmet eder. Acaba edebiyat o büyük, o mukaddes hizmeti nasıl ifâ ediyor? $\mathrm{Bu}$ sualin cevabı gayet basittir. Edebiyat insanı okumağa, okuya okuya fikirden lezzet almaya alıştırıyor. Zihin o sayede tatlı tatlı çalışıyor; çalıştıkça bir keyif, bir huzur, bir teceddüt hissediyor. Gitgide fikir daha ziyade inceliyor. Kalp daha ziyade rikkat buluyor. Nihayet en ince mülâhazat, en rakik hissiyat kolayca kabul ve

1 Buna bir örnek, A. Mithat'in Ahbar-ı Asara Tamim-i Enzar'ı̀ır.

2 Buna örnekse Ahbar-ı Asara Tamim-i Enzar'la aynı konu üzerine yazılmış ve tefrikası itibariyle ondan daha önce olan Halit Ziya’nın Hikâye adlı kitabıdır.

3 Kırk Ambar müellifine katılmak mümkün değildir. Tîn sûresini, 'edenin ettiğini bu dünyada bulması' diye okumak tarih boyunca hem sayısız zalimin zevk ü sefa içinde yaşayıp ölmesini ve çoğu erdemli, bilge insanın kuru ekmeğe muhtaç oluşunu göz ardı etmektir hem de sûrede va’z edilen ilkeyi, Hinduizm/Budizm'deki Karma prensibine indirgemektir. Mithat Efendi’nin bu görüşlere yer verdiği "Bir Gerçek Hikâye"den ve başka eserlerinden hareketle bu konuya eğilen önemli bir yazı için bkz.: Gökçek, Fazıl (2012), Küllerinden Doğan Anka, 43-60.

4 Nâbizâde Nâzım da romancının "terbiye-i vicdana hizmet" etmesi gerektiğini belirtir (N. Nâzım 2011: 419). Takdir-i Elhan'da da edebiyat ile "terbiye-i efkâr.. tasfiye-i vicdan..tehzîb-i ahlak" arasında neden-sonuç bağı, bir postüla olarak kabul edilir (Ekrem 2014: 18). 
telakki edilmeğe başlanıyor. Felsefenin, ulûm-1 içtimâiyyenin derin, haşin bir takım ahkâm ve gavâmızı -ki tetkik ve tefehhümüne bittabi herkes muktedir değildirşiirler, hikâyeler, tiyatrolar...hâsılı âsâr-1 edebiyye ve edebiyat sayesinde zihinlere giriyor yerleşiyor. Birçok mesâil-i hayatiye bu surette hallolunuyor. Birçok fezâil-i ahlâkiyye bu suretle intişar ve takarrur ediyor" (Tevfik Fikret 2000: 56) .

Burada/bu pasajda artık, sanatın, sanatsal estetiğin kendi etiğini kurmanın önünü açan türden bir düşünceyle karşı karşıyayızdır. Bu, hiç kuşkusuz bildik/ alışıldık türden bir etik değildir. Cenap Şahabettin ise 1914'te, Fikret'inkini başka/ ileri bir boyuta taşıyan tespitiyle dikkatlerimizi çeker. Herkesin, tamamıyla apolitik olduğunda ittifak ettiği Servet-i Fünûn edebiyatı, Cenap'a göre, "Yıldız Sarayı gibi metîn ve müstahkem bir şeyi -seng-i siyah-1 gafleti- rahnedâr edecekti. Dimağlar dimağlara inzimam ederek büyük bir meşcere-i tefekkür vücuda geliyordu. Artık Tevfik Fikret'i ve Halit Ziya'yı anlayarak okuyanlar lâkayd-1 terakki ve bîgâne-i mesai yaşayamazlardı; atâlet-i memleket kımıldamıştı. Netice herkesin malumudur" (Cenap Şahabettin 2011: 540). Son cümledeki kendinden emin tavır, bugün çoğu kimseye tuhaf görünecek bir inancın yansımasıdır. "Netice"den kasıt olarak, pekâlâ II. Meşrutiyet, Fecr-i Âti gibi yenilikçi atılımlar düşünebilir. Cenap, II. Abdülhamit idaresinin altını oyan temel faktörün Servet-i Fünûn edebiyatı olduğunu iddia etmektedir. Kuşkusuz o da, pür estetik endişeyle yapılan bir edebiyatın dahi kişiye, dünya ve şeylere dair etik, siyasî yönelimler/mesajlar telkin ettiğinden hareketle böyle bir iddiada bulunuyordu. Yaklaşık bir asır sonra ünlü düşünür J. Ranciere daha kes(k)in bir biçimde edebiyat-siyaset meselesine dair ve Cenap'a hak veren bir yorumda bulunacaktır: "Edebiyat, edebiyat olarak siyaset yapar. Bu ifade şunu varsayar: Yazarlar siyaset mi yapmalı yoksa kendilerini saf sanata mı adamalı sorularına gerek yoktur, çünkü bu saflık tam da siyasetle ilişkilidir; spesifik bir kolektif pratik biçimi olarak siyaset ile belirli bir yazma sanatı pratiği olarak edebiyat arasında özleri itibariyle bir bağ vardır. Siyasi faaliyet duyumsanabilir olanın paylaşımını yeniden şekillendirir. Ortak olanın sahnesine yeni nesneler ve özneler getirir. Evvelce görünmez olanı görünür kılar, önceleri yalnızca gürültülü hayvanlar

5 Fikret'in düşünceleri, Batı’da özellikle Ortaçağ boyunca hâkim olan bir görüşe paraleldir. Ortaçağ’da eserlerin -ister Kilise Babalarının olsun ister putperest Greko-Romen dünyanın eserleri olsun-; dilbilgisel çözümlenişi, anlamlandırılması ve nihayet metne dair geçmişte yapılmış yorumların mukayese edilmesi sürecinin insanı "daha iyi bir insan" yapacağına inaniliyordu (Manguel 2002: 98-99). 
olarak duyulanların sesinin, konuşan varlıkların sesi olarak duyulmasını sağlar. O halde edebiyatın siyaseti şu anlama gelir: Edebiyat zaman ve mekânın, görünür ve görünmezin, söz ve gürültünün bölümlenmesine edebiyat olarak müdahalede bulunur. Çeşitli pratikler, görünürlük formları ile ortak bir dünyayı ya da dünyaları bölen söyleme biçimleri arasındaki ilişkiye müdahalede bulunur" (Ranciere 2007: aktaran; Kılıç 2006: 52). ${ }^{6}$

Eğer sanatsal bir tür etik varsa bu, sanata mündemiç/immanent bir etiktir ve ondan ayırmak mümkün değildir. Söz konusu türden etik faydanın açığa çıkışı da; empati, erlebnis ${ }^{7}$ gibi kavramlarla ifade edilebilir. Orhan Pamuk'un, "roman yaza yaza başkalarının yerine kendimi koyarak ruhumu otuz beş yılda terbiye ettim" demesi bu türden bir etik faydanın dile getirilişidir (Pamuk 2011: 57). Kuşkusuz bu fayda okur için de geçerlidir. Kendimizi başkalarının yerine koyma, onları anlamak, onlar gibi düşünebilmek, duygusal eğitimin de temelidir. Böyle bir duygusal eğitim de elbette yaşama partikülerize eden bir yönden değil, maksimal, bütüncül açıdan yaklaşan; gündeliği değil asırlar boyu devam ede gelen zaafları ve yücelikleriyle 'insan'ı verebilen eserlerle gerçekleştirilebilir.

Etik ve estetik duraklarında hiç vakit kaybetmeden (!) bu iki disiplin arasındaki diyalektik ve çetrefil ilişkiyi, 'eserde mesaj verme' derekesine indirgeyerek vülgarize etmek de meselenin derinliğini kavramaktan uzak bir tutumdur. Eğer mesele, emr-i bi'l ma'ruf nehy-i ani'l münker yahut irşad ü tebliğse, neden bunları içine yerleştirdiğimiz ve okurun zihnine ulaşmak için kullandığımız bir boru (edebî söylem) ya ihtiyaç duyarız? Nasihat dinlemekten hoşlanmayan insan tabiatının nankörlüğü ve kofluğu, insanı anlatma ve anlama skalasında başta gelen edebiyatın sayısız niteliklerinden bir kısmını âtıl bırakmayı haklı çıkarmaya yeter mi? Doğrudan, dolaysız nasihat ile edebiyat iki bağımsız diskur olarak yaşasalar, 'nasihat' ne kaybeder? Dahası ve önemlisi; her iki diskurun mezcedilmesi, her ikisinin de enerjisinin aleyhine işleyen türden bir karışımla neticelenir mi? Acaba 'mesaj', belli estetik/sanatsal vazifeler yerine getirildikten, belli edebî duraklara uğrandıktan sonra eserde -hem yazar hem okur için- varılacak nokta mıdır?

6 Son olarak benzeri bir görüşü daha aktaralım: "Sanırım, şiir ve siyaset, birbirlerinden farklı şekillerde, dağınık inanışlara, önyargılara, hayat görüşlerine ve benzeri șeylere bir şekil veriş, bunları dile getiriş, düzenleyiştir (Heaney 2017: 15).

7 'Erlebnis' için bkz.: Wellek, René (1971), Discriminations, 225-252. 
Bunlara ve bunlara benzer daha başka sorularla mesaj-sanat ilişkisini sorunsallaştırmayan, bu sorunsalla cedelleşmeyen bir zihniyetten doğacak sanatsal faaliyet de hem kalıcı olmayacaktır, hem de onun bir kanadı eksik kalacaktır. ${ }^{8} \mathrm{Bu}$ sorunsaldan ikinci bir çıkış yolu daha vardır, o da yukarıda zikredilen ve NLP kitaplarında anlatılan türünden tamamen uzak, empatidir. Sanatçının kendisini, kendisi gibi olmayanların/yaşamayan ve düşünmeyenlerin yerine koyabilmesi ve bu yolla onları anlama(ya çalışma)sıdır. Bu; ruhî, içsel bir terbiye ve hesaplaşmayı ve hesaplaşma sürecinde de kişinin kendi dünyasını başkalarınınkiyle yan yana koyması sonucunda belki de duygusal/düşünsel anlamda ödün vermesini gerektirecek bir durumdur. Diğer bir deyişle, kendini başkalarının yerine koymak, zor ve bedel ödemeyi gerektirebilecek bir tecrübedir. Kimi sanatçılarda bu tecrübe, bir bakıma Allah vergisi, organik bir yetenek gibidir; Akif’te görüldüğü gibi. ${ }^{9}$ Kimilerinde ise sanatı yaşamlaştırma-ya da yaşamı estetize etme- gayretinin sonucunda, uzun yılların birikimiyle oluşan entelektüel bir beceridir; Orhan Pamuk’ta olduğu gibi.

Estetik tecrübe ister istemez aynı zamanda bir tür etik tecrübe olacaktır. Belki de bu yüzden, hem Doğu'da hem Batı'da bunun farkında olanlar, roman okumayı bazı gruptan kimselere -kadınlar, reşit olmamış gençler vb.- yasaklamak istemişlerdi. ${ }^{10}$ Okumak, okunan kurmaca olsa da ve okuru somut, olgusal durumların içine koymasa dahi, kişiyi duygusal ve entelektüel boyutta hipotetik, farazi kimi problem(atik)lere muhatap kllacaktır. ${ }^{11}$ Okurun bunlar üzerine spekülatif olarak düşünmesi, kurmaca karakterlerin duygularının simülasyonunu kendi iç dünyasında yeniden yaratması/yaşaması, pek çok kimsece hoş karşılanmayacaktır. Ancak bu,

8 Böyle bir cedelleşme ve zikredilen sorular üzerine düşünmek için mükemmel bir başlangıç Ahmet İnam’ın ufuk açıcı yazısı olabilir. Bu yazıda sıkça kullanılan, "edebiyatın edebiyatla(yama)ması" ifadesinin altında yatan birçok âmilden birisi de, edebiyatın "inanç sistemlerini desteklemek için” kullanılan bir "duygusal etkileme aracı" olarak görülmesidir (İnam 2003: 25). İnanç ve roman yahut etik ile estetik arasındaki etkileşimin, ilişkinin çözülmesi hiç de kolay olmayan bir sorunsal olduğu konusunda ayrıca bkz.: W. C. Booth, "Gayrışahsi Anlatı Ahlakı" Kurmacanın Retoriği, çev.: B. O. Doğan, 2012, Metis yay., s. 389-409.

9 Kasdettiğimiz türden bir empatiyi yansıtan, Akif'in şu ünlü dizeleridir: "Bir mülhidi lâkin kim eder tesliye heyhât? / Sığmaz bunun âfâkına ferdâ-yı mükâfât! / Baştan başa "boşluk" şu semâlar, şu zeminler, / Bir gûş-i kerem var mı akan yaşları dinler? (...) Mülhidlere lâkin daha çok merhamet eyle: / Gümrâhlarındır ki karanlıklara dalmış, (...) Mülhid de senin, kalb-i muvahhid de senindir" (Ersoy 2007: 66, 67). Kötü, savruk, günahkâr bir yaşamdan sonra 'doğru yol’a girenleri anlatan sayısız roman yazılmıştır edebiyatımızda. Peki ya sürecin tersinden işlediği hayatlar? 'Doğru yol'da uzun süre seyrettikten sonra, dışsal yahut içsel sebeplerle, kontrolünü yitiren karakterleri ve onların yitişindeki trajediyi anlatacak nitelikli romanlar? Böyle bir roman için, en azından romancının ufkunun şu noktaya ulaşabilmesi gerekir: "Bu dünyada günahın da bir ödevi vardır: sevabı, toy bir sevap olmaktan kurtarır. Sevap denene denene sağlamlaşır” (Karakoç 2016: 36). 10 Bu konuda, Doğu’dan ve Batı'dan çok sayıda örneğin irdelendiği bir eser için bkz.: Andı (2010), Roman ve Hayat.

11 "Kitap okumak bir yaşantıdır, sözgelimi bir kadına bakmak, âşık olmak, sokakta yürümek gibi bir yaşantı. Kitap okumak bir yaşantıdır, çok gerçek bir yaşantı” (Borges 2017: 170). 
kişiyi kendi inandıkları ve hissettiklerini ilk kez karşılaştığı bazı değer ölçütlerine vurma imkânı sağlayan ve böylece insanı 'medenîleştiren' bir tecrübedir. İşin etik boyutu da bu noktada açımlanır. J. Benda tam da bu nokta üzerine dikkate değer tespitini yaklaşık bir asır önce şöyle dile getirmişti:

\begin{abstract}
"Romancıları ve oyun yazarlarını kastediyorum; yani görevleri, insan ruhunun duygularını ve çatışmalarını olabildiğince nesnel bir şekilde tasvir etmek olan aydınları-(...) Birçok çağdaş romancının bu görevi siyasi amaçlara tâbi kılarak şimdiye dek olduğundan çok daha fazla saptırmakta olduğu söylenebilir; ama bunun nedeni yapıtlarına 'yanlı' düşünceler serpiştirmeleri değildir (ki Balzac bunu sürekli yapar), bilakis kahramanlarının duygularını ve davranışlarını insan doğasına ilişkin geçek bir gözleme dayandırmak yerine, kendi ihtiraslarına uydurmalarıdır. Gelenekçilerin, düştükleri hata ne olursa olsun, sonunda daima soylu bir ruh sergilediği ve dinsiz karakterin tüm çabasına rağmen kaçınılmaz olarak kötü eylemlerde bulunmaya yazgılı olduğu romanları zikretmeme gerek var mı? Ya da yazarın yabancılarla ilişki halindeki yurttaşlarını anlattığı ve bir tür içtenlikle, kendi insanlarını ahlaki açıdan üstün gördüğü romanları? Bu yaklaşımda iki türlü kötülük vardır; okuyucunun gönlünde siyasi ihtirası had safhada alevlendirmekle kalmaz, bunun yanı sıra okuyucuyu tüm sanat yapıtlarının en önemli medenileştirici etkilerinden birinden de yoksun bırakır; yani her okuyucu, doğru olduğunu hissettiği ve sadece hakikatle dolu olduğunu düşündüğü bir insan temsili ile bir iç hesaplaşmaya sürüklenir" ( 2006: 57-58, vurguların tamamı bize ait).
\end{abstract}

Oysa kurmaca eserler hakikatin dillendirildiği kürsüler olmak yerine insan ruhuna dair hakikatler içermelidir. Böylece okuyucu da kurmacanın aynasında kendini daha net görebilecektir. Bu sözlerden hareketle kurmacanın sularında seyretmenin sadece okur için değil elbette yazar için de riskli olduğunu eklemek gerekir. Yukarıda sadece imâ edilen problem(atik)leri -ki bunlardan biri 'kötülük'tür ${ }^{12}$ - kendi içinde ve anlatıda bastıran yahut bir Yeşilçam filmi naifliğiyle çözüme kavuşturan (!) yazar, iki türlü kayıptadır. Hem kendini kendisine anlatma hem de 'öteki'ni anla(t)manın hakkını verememiştir. Oysa estetiğin etikle (yegâne?) buluşma noktası da buradadır; eğer anlatı içindeki ahlak, ideoloji, inanç diskurlarından sarf-ı nazar edersek. Zira kendi ahlakımızın, ideoloji yahut inandıklarımızın anlatı içinde karakterler aracılığıyla onandığını görmek ve yaşamak, okuru yüceltmeyeceği gibi, edebiyatın potansiyel enerjisinden ortaya çıkabilecek aydınlanışla da kıyas kabul etmeyecek kadar

12 Edebiyat(ç)ımızın kötülük sorununu bastırdığı , yeterince üzerine gitmediği/işlemediği ve hatta bunu bir imkân olarak değerlendir(e)mediği konusunda, sunulduğu tarihten bugüne kadar hâlâ atıf yapılan ve tartışlan bir metin için büyük sosyolog Şerif Mardin’in tebliğine bakılabilir (2001: 21-32). 
küçük bir tatmine kanaat etmektir. Çoğu yazarımızın ıskaladığı edebî/kurgusal hakikat şuradadır: "Hikâyede, olay ne olursa olsun, zaferi kim kazanırsa kazansın, yenilen kim olursa olsun, gerçek zafer, estetik ve fikirsel sonuçtadır. Hikâye; okuru etkilemiş, onun adalet duygularını ayağa kaldırmışsa, hikâyede iyi, kötüye yenilse bile sonuç olumludur" (Aymatov 1991: 166). Bu "estetik ve fikirsel" olanla ilgili olarak, dahası da vardır: "Birçok terbiyecinin ilk yanlışı, ihtiraslarından söz açmamak, onları yok etmek olduğuna inanışlarında değil midir? Bir manastırın duvarları arasında beslenen, kitapsız, gazetesiz bir delikanlının, hepsini birden yoktan var edeceğinden şüphe etmeyiniz. Çünkü hepsini kendisinde taşımaktadır. Ne yazık ki, içimizde saltanat süren yalnız Allah değildir. (...) Romandan (...) Şeytan'ı sürmek imkânsızdır”' (Mauriac : $56,57)$.

Yazdığı her kelimede samimi olduğunu, gerçekten hissettiklerini yazdığını ve eserinin gücünü buradan aldığını düşünen yazar/şair yanılgı içindedir. Samimiyet, etikle ilgilidir ve etikle ilgili bir konuda bazı ifade ve değerleri tartmada işlevseldir. Ancak sanata taşındığında aynı ağırlığı, etkiyi bırakmayacaktır. "Samimiyet veya samimiyetsizlik, edebiyat söz konusu olduğunda, etikle değil estetikle alakalı bir meseledir" (Llosa 2014: 42). Gündelik yaşamda samimiyet, bizi etkilemek yahut harekete geçirmek için yeterli olur çoğu kez. Edebiyatta ise bunlar, Flaubert'in deyişiyle "mot juste”le gerçekleşir. Yani “doğru sözcük”lerle. Dolayısıyla edebiyat, yazarın; bir düşünceyi, duyguyu "tamı tamına ifade etmek için kullan"dığı ve "başlıca yükümlülüğünün” doğru sözcükleri bulma uğraşısıyla samimiyet kesbettiği bir alandır (Llosa 2014: 44, 45). Üstelik bu samimiyet yahut yazarın/şairin sözcüklere göstermesi gereken sadakat, çok üst düzeyde, kıskançça bir beklenti içindedir, yazarı/şairi tüketir, başka kimselere, dünyada birakmaz. ${ }^{13}$

13 Bu durumun ifade edilişine bir örnek: "Size yazmayı buyuran nedeni araştırıp ele geçirmeye bakınız. Yüreğinizin ta en dip köşesinde kök salıp salmadığını araştııınız bu nedenin. Yazmanız diyelim yasaklandı, ölür müydünüz o zaman ya da yaşar mıydınız eskisi gibi, bunu açıklayın kendi kendinize. Özellikle şunu yapın: Gecelerinizin en kuytu saatinde kendinize şu soruyu yöneltin: İlle de yazmam gerekiyor mu? Deşin içinizi, diplere inin, derinlerden bir yanıt ele geçirmeye çalışın. Ve bu yanıt onaylayıcı nitelik taşıyorsa, sorduğunuz sorunun karşısına, 'Evet, yazmam gerekiyor' gibi güçlü ve yalın bir yanıtla çıkabiliyorsanız, o zaman bu zorunluluğa göre kurun yaşamınızı; en sudan, en değersiz saatine varıncaya dek yaşamınızı bu içsel dürtünün simgesi ve kanıtı yapın” (Rilke 2007: 38). Bize göre sanat(çın)ın başlıca etik sorunsalı burada yatmaktadır. Bu türden bir nefis muhasebesine giriş(e)meyen edebiyatçımız, kendisi 'ol'madan/kendi olmadan, başkalarını oldurmaya çalışan bir Molla Kasım profili çizmektedir 
Sanatçı sanatının somutlaştığı kelimeleri kullanmadan önce, onları tartacak, yoklayacak en uygun kelimeyi seçmek için sayısız, çoğu kez bıktırıcı deneyler yapacaktır. Böylece, bir diğer önemli etik sorunla yüzleşir sanatçı; dil. Kuşkusuz, etik ile 'dil'i yan yana getirmenin, Kutuplarda portakal yetiştirmek kadar anlamsız, gereksiz olduğunu düşünecek kişiler, bizim hipotetik sanatçımızdan tamamen uzaktırlar. Onlar ve onlar gibi düşünen edebiyatçılar, her ne kadar 'hakikati dile getirme'nin öncelikli olduğunu düşünseler de bu dile getirişin kendilerine yükledikleri bireysel sorumluluktan da sanatçı olmanın bağımlı kıldığı zorunluluklardan da bîhabedir. 


\section{Kaynakça}

Ahmet Mithat (2001), Letaif-i Rivayat, hzl. Fazıl Gökçek-Sabahattin Çağın, Çağrı yayınları. And1, Fatih (2010), Roman ve Hayat, Akademik Kitaplar, 3. bs.

Aytmatov, Cengiz (1991), Beyaz Gemi, çev. Refik Özdek, Ötüken yayınları, 62. bs.

Benda, Julien (2006), Aydınların Ihaneti, çev. Cem Soydemir, Doğu-Batı yayınları.

Borges Sekseninde (2017), Editör: W. Barnstone, çev. Celâl Üster, Can yayınları.

Cenap Şahabettin (2011), “Büyük Hasta”, Yeni Türk Edebiyatı Metinleri 3, hzl. İnci EnginünZeynep Kerman, Dergah yayınlar1, 539-542.

Ersoy, Mehmet Akif (2007), Safahat Birinci Kitap, hzl. Fazıl Gökçek, Dergah yayınları.

Gökçek, Fazıl (2012), “Ahmet Mithat Efendi’nin Hikâye ve Roman Anlayışı” Küllerinden Doğan Anka, Dergah yayınları, 43-60.

Heaney, Seamus (2017), Kuzey, çev. Mustafa Bal, Hece yayınları.

İnam, Ahmet (2003), "Ebediyâtını Yitirmiş Edebiyât: Edebiyâtın Edebi Yatık mı?” Doğu Batı, S. 22, 21-36

Karakoç, Sezai (2017), Kıyamet Aşısı, Diriliş yayınları, 15. bs.

Kılıç, Savaş (2006), "Hazzın Geceye Sürgünü: Edebiyat ve Siyaset Üstüne Notlar” Notos Öykü, S. 59, 50-55.

Llosa, M. Vargas (2014), Genç Bir Romancıya Mektuplar, çev. Emrah İmre, Can yayınları.

Manguel, Alberto (2002), Okumanın Tarihi, çev. Füsun Elioğlu, YKY, 2. bs.

Mardin, Şerif (2001), “Genel Hatlarıyla Modernleşme” Modernleşme, İslam Dünyası ve Türkiye'nin içinde, Editör: Sabri Orman, Ensar Neşriyat.

Nâbizâde Nâzım (2014), "Roman ve Romanc1", Yeni Türk Edebiyatı Metinleri 3, hzl. İnci Enginün-Zeynep Kerman, Dergâh yayınları, 419-421.

Mauriac, François (2006), "Roman”, Din ve Sanat'in içinde, çev. Burhan Toprak, Hece Yayınları, 2. bs.

Mizanc1 Murat (1994), “Üdebâmızın Nümune-i İmtisâlleri”, Yeni Türk Edebiyatı Antolojisi III'ün içinde, hzl. Mehmet Kaplan vd., Marmara Üniversitesi, 379-440.

Pamuk, Orhan (2011), Saf ve Düşünceli Romancı, İletişim yayınları.

R. Mahmut Ekrem (2014), Takdir-i Elhan, hzl. Hakan Sazyek vd., Umuttepe yay.

Rilke, R. M. (2007), Çünkü Zordur Sevgi, çev. Kâmuran Şipal, Cem yayınları.

Tevfik Fikret Dil ve Edebiyat Yazıları (2000), hzl. İsmail Parlatır, TDK.

René, Wellek (1971), "Genre Theory, the Lyric and Erlebnis", Discriminations, Yale University Press, 225-252. 